\title{
Topical Application of 5-Fluorouracil Associated with Distant Seborrheic Dermatitis-like Eruption: Case Report and Review of Seborrheic Dermatitis Cutaneous Reactions after Systemic or Topical Treatment with 5-Fluorouracil
}

Tyler Werbel · Philip R. Cohen

Received: June 20, 2018 / Published online: July 26, 2018 (C) The Author(s) 2018
Enhanced Digital Features To view enhanced digital features for this article go to https://doi.org/10.6084/ m9.figshare.6833483.

T. Werbel $(\bowtie)$

School of Medicine, University of California San

Diego, La Jolla, CA, USA

e-mail: tylerwerbel@gmail.com

P. R. Cohen $(\varangle)$

Department of Dermatology, University of

California San Diego, La Jolla, CA, USA

e-mail: mitehead@gmail.com
Discussion: Several case reports have been published which describe exacerbations of preexisting seborrheic dermatitis with local topical 5-fluorouracil. Additionally, one case series describes the development of scrotal dermatitis in two patients after distant treatment with 5-fluorouracil. The pathogenesis that causes this distant reaction is unclear.

Conclusion: We describe a patient with a seborrheic dermatitis eruption after topical application of 5-fluorouracil at a distant site. The etiologic association between the drug and adverse effect was confirmed with multiple cycles of application and discontinuation of the offending agent.

Keywords: Actinic; Dermatitis; 5-Fluorouracil; Keratosis; Seborrheic; Topical; Toxicity

\section{INTRODUCTION}

5-Flurouracil is a pyrimidine antimetabolite; topical preparations of this agent are used in the treatment of actinic keratosis [1]. Seborrheic dermatitis is an inflammatory papulosquamous dermatosis, and although it may affect the scalp and anterior chest, many patients exhibit only facial manifestations of this condition [2]. Herein we describe a man with actinic keratoses on his arms, and no similar lesions or history of seborrheic dermatitis on his face, who developed a facial seborrheic dermatitis-like 
dermatosis after applying 5-fluorouracil topically to actinic keratoses on his arms. We also review seborrheic dermatitis-like eruptions secondary to systemic or topical 5-fluorouracil.

Informed consent was obtained from the participant for being included in the study.

\section{CASE REPORT}

A 63-year-old man presented for evaluation and treatment of asymptomatic lesions on his distal upper extremities. His past medical history was significant for nephrolithiasis and hypertension, for which he had been taking amlodipine and triamterene-hydrochlorothiazide for many years. He also had a history of a basal cell carcinoma and a squamous cell carcinoma on his arms; both were excised 5 years earlier, and there has been no recurrence. The patient had scaling of his eyebrows 20 years ago which had spontaneously resolved; he otherwise had no prior history of seborrheic dermatitis. He had no recent sunburn or rash on his face.

Cutaneous examination showed erythematous scaly plaques on his bilateral forearms from just above the elbow to the dorsal hands. There was no scaling or erythematous lesions on his scalp, face, chest, or back. Based on clinical morphology, the diagnosis of actinic keratoses was established.

After a discussion of treatment options, including liquid nitrogen cryotherapy, photodynamic therapy, and topical agents (diclofenac, 5-fluorouracil, imiquimod, or ingenol mebutate), the patient elected to proceed with topical 5-fluorouracil 5\% treatment. The initial treatment was twice daily for 7 days to be repeated every 2 months until his 6-month follow-up visit. He had an excellent response to treatment, with erythema and crusting of his actinic keratoses after the first treatment. At completion of therapy, mupirocin $2 \%$ ointment was used twice daily until the area returned to normal.

Four and six months after the follow-up appointment, the patient retreated the forearm actinic keratoses with 5-fluorouracil 5\% cream twice daily. On the seventh day of therapy in each treatment cycle, he noted asymptomatic erythema and scaling on his face. Cutaneous examination revealed erythematous scaling plaques involving the glabellar areas, malar cheeks, paranasal regions, upper lip, and perioral region with extension to the chin (Fig. 1). His arms showed hyperpigmentation in sunexposed areas on his arms bilaterally. There was diffuse scaling and superficial desquamation of the extensor forearms bilaterally (Fig. 2).

The 5-fluorouracil was discontinued, and mupirocin $2 \%$ ointment was applied to the forearms twice daily. Both arms and face promptly returned to their normal appearance, the latter without topical intervention.

Laboratory evaluation revealed normal complete blood cell count, including white blood cell count. His serum chemistries, including liver function, were normal. Evaluation of dihydropyrimidine dehydrogenase (DPD) enzyme showed a normal genotype. The three most common variants that have been consistently associated with 5-fluorouracil toxicity are c.1679T $>\mathrm{G}, \quad$ c.2846A $>\mathrm{T}$, and c. $1905+1 \mathrm{G}>\mathrm{A}[3,4]$; none of these gene mutations were detected in this individual.

Correlation of the history and morphologic features established a diagnosis of seborrheic dermatitis-like eruption on the face secondary to topical application of 5-fluorouracil at the distant site of his bilateral forearms. The patient had elected to challenge the initial observation with repeated treatment, which resulted in similar consequences, confirming the suspicion that the reaction was caused by 5-fluorouracil.

Despite the repeated development of seborrheic dermatitis-like facial eruption after applying 5-fluorouracil, the patient was curious about this adverse effect. Therefore, 2 months later, he elected to treat his buttocks twice daily with 5-fluorouracil. After 5 days of therapy, there was no reaction on his buttocks or his face, so he discontinued the medication.

He subsequently proceeded to again treat his forearm actinic keratoses. However, since the facial eruption had occurred after 7 days of therapy, he only treated his forearms for 5 days. During the fourth day of application, he developed similar erythematous plaques and scaling on his face with this shortened treatment 


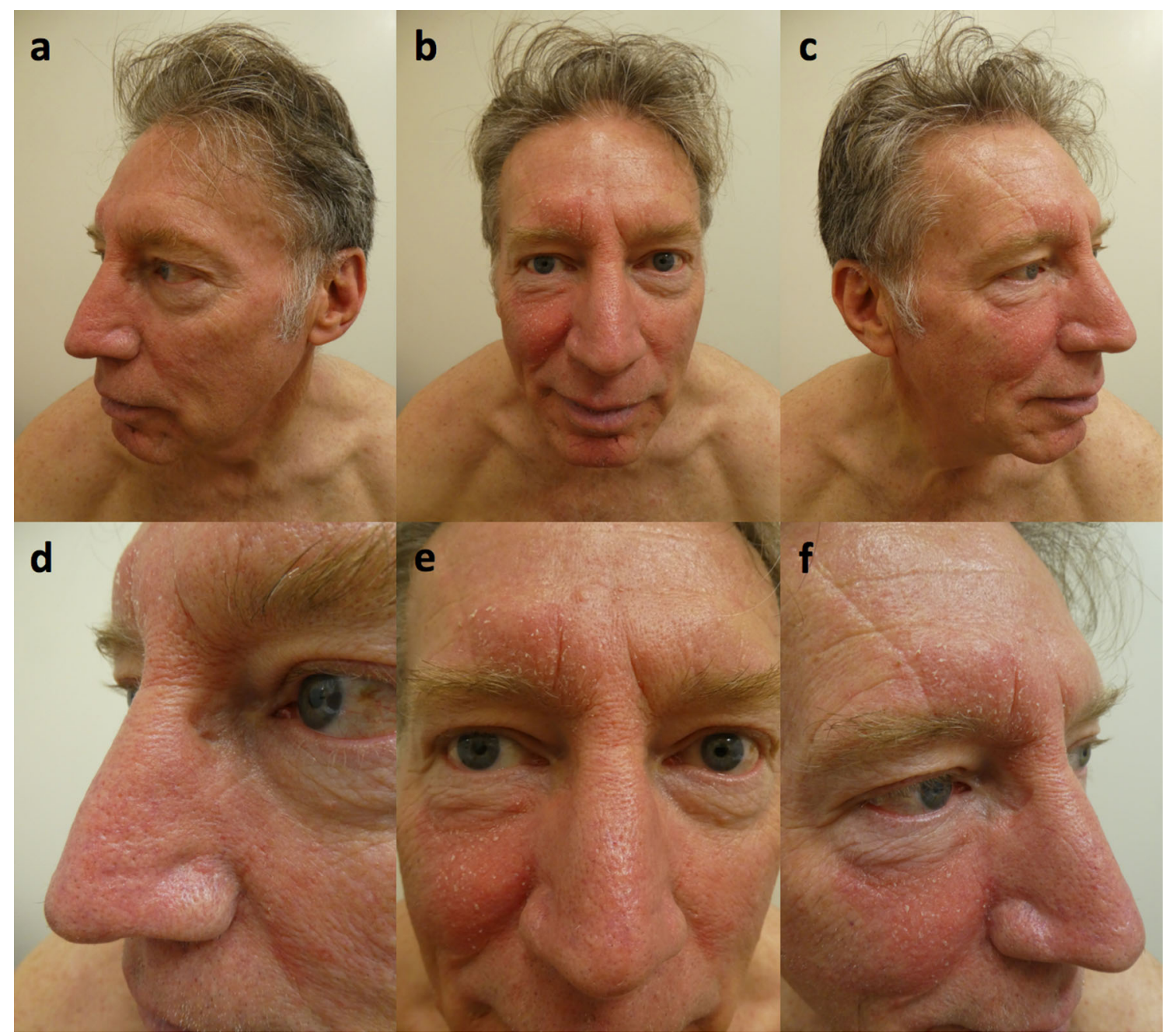

Fig. 1 Distant $(\mathbf{a}, \mathbf{b}, \mathbf{c})$ and closer $(\mathbf{d}, \mathbf{e}, \mathbf{f})$ views of the face of a 63-year-old man shows a seborrheic dermatitis-like eruption following the topical application of 5 -fluorouracil on his arms

regimen. The 5-fluorouracil was stopped on the fifth day, and the seborrheic dermatitis slowly resolved.

\section{DISCUSSION}

5-Fluorouracil is an antineoplastic agent. As a uracil analog, the drug inhibits both DNA and RNA synthesis by preventing the incorporation of uracil into RNA, and it also inhibits thymidylate synthase, an enzyme required for converting deoxyuridine monophosphate to deoxythymidine monophosphate, a component of DNA [1].
Systemic 5-fluorouracil has been used as an integral component of monotherapy or combination chemotherapy in patients with either colon or breast cancer [5]. It was observed that patients treated with systemic 5-fluorouracil developed inflammation and then resolution of actinic keratoses; this prompted the development of topical 5-fluorouracil for this skin condition $[6,7]$.

Metabolism of 5-fluorouracil is dependent upon its degradation by dihydropyrimidine dehydrogenase, an enzyme encoded by the $D P Y D$ gene that reduces 5 -fluorouracil to the inactive dihydrofluorouracil [8]. In patients with a deficiency or abnormal variants of DPYD, 


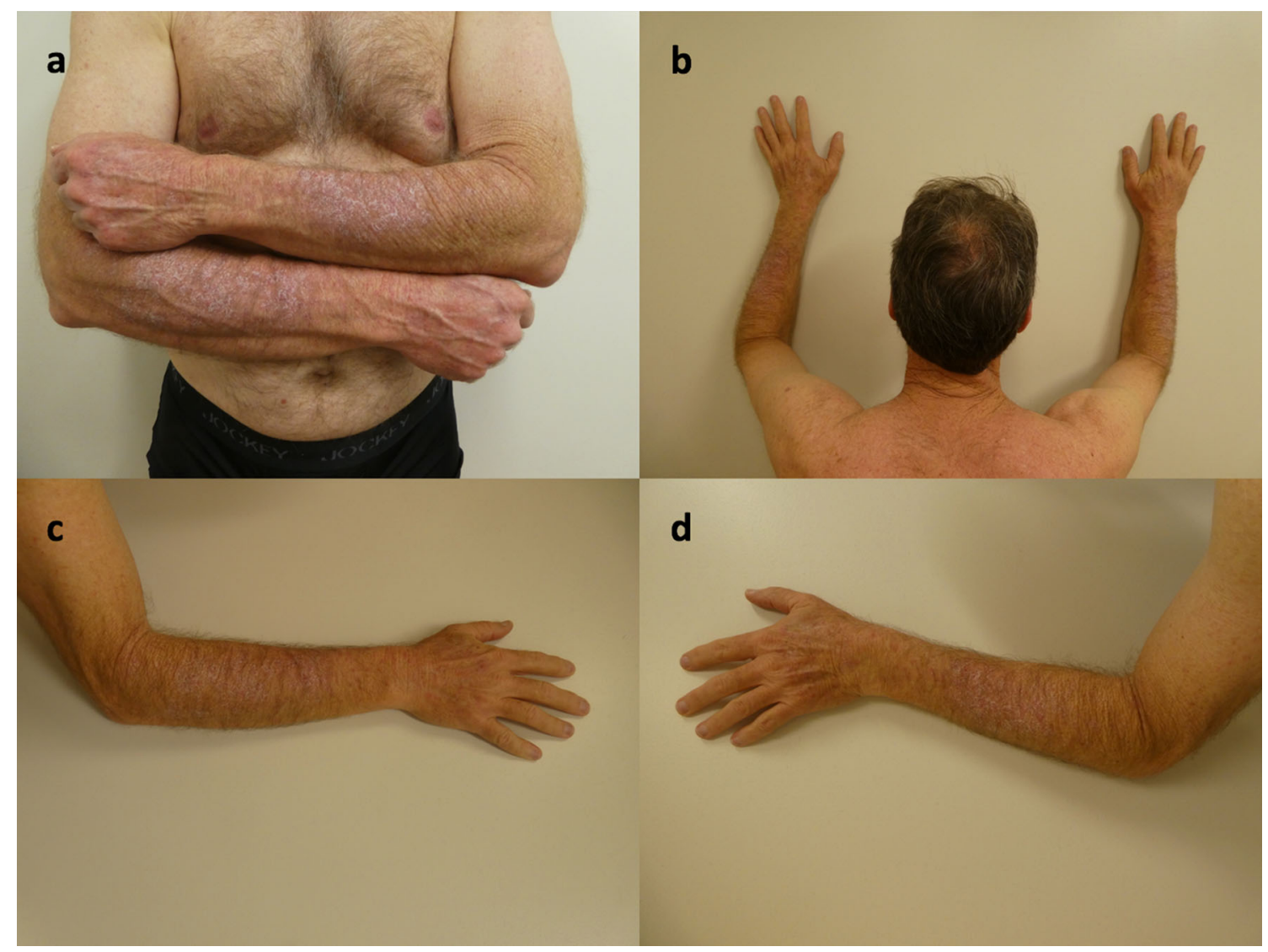

Fig. 2 Front (a) and back (b) views of a 63-year-old man shows his extensor forearms after topical treatment with 5-fluorouracil. Hyperpigmentation and scaling erythematous plaques are present on the right (c) and left

the response to 5-fluorouracil is greater. Similarly, the adverse effects are also more prominent [3].

Topical 5-fluorouracil is associated with the following cutaneous adverse effects: allergic contact dermatitis, conjunctivitis, corneal irritation, erosions, hyperpigmentation, hypopigmentation, irritant dermatitis, onycholysis, photosensitivity, and secondary bacterial infections [9-11]. There are also several reports of individuals with a prior history of facial seborrheic dermatitis or rosacea experiencing a flare of their dermatosis after application of 5-fluorouracil to their face [12-14]. Systemic 5-fluorouracil has also been associated with flares of seborrheic dermatitis, particularly in patients who have active dermatitis or a history of the condition [15, 16]. Seborrheic dermatitis (d) extensor forearms, consistent with 5-fluorouraciltreated actinic keratoses, are noted

eruptions have also been observed in patients treated with other systemic antineoplastic agents (Table 1) [13, 16-26].

Our patient is unique in that he had no prior history of seborrheic dermatitis and had no previous actinic keratoses on his face. However, he developed a seborrheic dermatitis-like dermatosis on his face after application of topical 5-fluorouracil at the distant site of his forearms; there was no inadvertent application of the medication to his face. He was very pleased with the efficacious response of the 5-fluorouracil treatment to his forearm actinic keratoses and therefore elected to repeat the treatment; recurrence of the seborrheic dermatitis-like dermatosis after rechallenge with topical 5-fluorouracil confirmed the suspected etiologic association. Based upon the Naranjo adverse 
Table 1 Systemic antineoplastic agents associated with seborrheic dermatitis

\begin{tabular}{l}
\hline Antineoplastic agents \\
\hline Antimetabolites \\
5-Fluorouracil (systemic and topical) \\
BRAF kinase inhibitor \\
Vemurafenib \\
Epidermal growth factor receptor inhibitors \\
Cetuximab \\
Erlotinib \\
Gefitinib \\
Immunomodulators \\
Interferon- $\alpha$ \\
Interleukin-2 \\
Thalidomide \\
Tyrosine kinase inhibitors \\
Dasatinib \\
Sorafenib \\
Sunitinib \\
\hline
\end{tabular}

drug reaction probability scale, our patient's score is 7 , which indicates a probable association between the drug and adverse event [27].

The development of a dermatosis at a distant site without concurrent actinic keratoses after application of topical 5-fluorouracil is unusual. However, Shelley and Shelley described a similar phenomenon in men who were applying topical 5-fluorouracil to their face, arms, or legs and subsequently developed dermatitis of their scrotums [28]. At least two of the four men had not inadvertently applied the medication to their scrotum or to skin that came in contact with the scrotum. Similar to our patient, the cutaneous adverse event occurred on the skin that had not previously experienced dermatosis and did not have actinic keratoses; in addition, there was no history of sun exposure to the affected area of the scrotum [28].
Low or deficient DPD activity is estimated to have a prevalence of 3-5\% in the general population [29]. Reduced DPD activity results in increased serum concentrations of 5-fluorouracil, thus increasing the risk of severe and sometimes lethal adverse effects, including central neurotoxicity, diarrhea, mucositis, neutropenia, and thrombocytopenia [30]. However, the DPD genotype in our patient was normal. A DPD evaluation was not performed in the patients described by Shelley and Shelley [28].

\section{CONCLUSIONS}

Topical 5-fluorouracil has been associated with adverse cutaneous side effects. Albeit infrequently reported, application of the agent to the face in patients with active actinic keratoses or a history of actinic keratoses may exacerbate the underlying condition. However, our patient's presentation is unique since he developed the seborrheic dermatitis-like dermatosis following treatment of his forearms-a distal site without any inadvertent contact with his face-and despite an absence of prior facial dermatitis.

\section{ACKNOWLEDGEMENTS}

Funding. The authors are fully responsible for all content and editorial decisions and received no financial support or other form of compensation related to the development or publication of this manuscript.

Authorship. All named authors meet the International Committee of Medical Journal Editors (ICMJE) criteria for authorship of this manuscript, take responsibility for the integrity of the work as a whole, and have given final approval for the version to be published. No funding was received for publication of this article.

Disclosures. Tyler Werbel and Philip R. Cohen have nothing to disclose with regards to the publication of this article. 
Compliance with Ethics Guidelines. Informed consent was obtained from the participant for being included in the study.

Open Access. This article is distributed under the terms of the Creative Commons Attribution-NonCommercial 4.0 International License (http://creativecommons.org/licenses/ by-nc/4.0/), which permits any noncommercial use, distribution, and reproduction in any medium, provided you give appropriate credit to the original author(s) and the source, provide a link to the Creative Commons license, and indicate if changes were made.

\section{REFERENCES}

1. Longley DB, Harkin DP, Johnston PG. 5-Fluorouracil: mechanisms of action and clinical strategies. Nat Rev Cancer. 2003;3(5):330-8.

2. Gupta AK, Bluhm R, Cooper EA, Summerbell RC, Batra R. Seborrheic dermatitis. Dermatol Clin. 2003;21(3):401-12.

3. Amstutz U, Froehlich TK, Largiadèr CR. Dihydropyrimidine dehydrogenase gene as a major predictor of severe 5-fluorouracil toxicity. Pharmacogenomics. 2011;12(9):1321-36.

4. Meulendijks D, Henricks LM, Sonke GS, et al. Clinical relevance of DPYD variants c.1679T $>\mathrm{G}$, c.1236G > A/HapB3, and c.1601G > A as predictors of severe fluoropyrimidine-associated toxicity: a systematic review and meta-analysis of individual patient data. Lancet Oncol. 2015;16(16):1639-50.

5. Vaitkevicius VK, Brennan MJ, Beckett VL, Kelly JE, Talley RW. Clinical evaluation of cancer chemotherapy with 5-fluorouracil. Cancer. 1961;14:131-52.

6. Falkson G, Schulz EJ. Skin changes in patients treated with 5-fluorouracil. $\mathrm{Br} \mathrm{J}$ Dermatol. 1962;74:229-36.

7. Omura EF, Torre D. Inflammation of actinic keratoses due to systemic fluorouracil therapy. JAMA. 1969;208(1):150-1.

8. Caudle KE, Thorn CF, Klein TE, et al. Clinical pharmacogenetics implementation consortium guidelines for dihydropyrimidine dehydrogenase genotype and fluoropyrimidine dosing. Clin Pharmacol Ther. 2013;94(6):640-5.
9. Dillaha CJ, Jansen GT, Honeycutt WM, Bradford AC. Selective cytotoxic effect of topical 5-fluorouracil. Arch Dermatol. 1963;88:247-56.

10. Goette DK. Topical chemotherapy with 5-fluorouracil. A review. J Am Acad Dermatol. 1981;4(6):633-49.

11. Cohen PR. Topical application of 5-fluorouracil 5 percent cream associated with severe neutropenia: discussion of a case and review of systemic reactions after topical treatment with 5-fluorouracil. Dermatol Online J. 2018;24(4).

12. Dong JA, Brodell RT. Exacerbation of seborrheic dermatitis following topical 5-fluorouracil. J Geriatr Dermatol. 1996;4(1):7-10.

13. Brodell EE, Smith E, Brodell RT. Exacerbation of seborrheic dermatitis by topical fluorouracil. Arch Dermatol. 2011;147(2):245-6.

14. Haddock ES, Cohen PR. 5-Fluorouracil-induced exacerbation of rosacea. Dermatol Online J. 2016;22(11).

15. Vukelja SJ, James WD, Weiss RB. Severe dermatologic toxicity from 5-fluorouracil in the presence of seborrheic dermatitis. Int $\mathrm{J}$ Dermatol. 1989;28(5):353-4.

16. Dudley K, Micetich K, Massa MC. Erythema with features of seborrheic dermatitis and lupus erythematosus associated with systemic 5-fluorouracil. Cutis. 1987;39(1):64-6.

17. Huang V, Hepper D, Anadkat M, Cornelius L. Cutaneous toxic effects associated with vemurafenib and inhibition of the BRAF pathway. Arch Dermatol. 2012;148(5):628-33.

18. Pinto C, Barone CA, Girolomoni G, et al. Management of skin toxicity associated with cetuximab treatment in combination with chemotherapy or radiotherapy. Oncologist. 2011;16(2):228-38.

19. Benomar S, Boutayeb S, Afifi Y, et al. Hand-foot syndrome and seborrheic dermatitis-like eruption induced by erlotinib. Dermatol Online J. 2009;15(11):2.

20. Graves JE, Jones BF, Lind AC, Heffernan MP. Nonscarring inflammatory alopecia associated with the epidermal growth factor receptor inhibitor gefitinib. J Am Acad Dermatol. 2006;55(2):349-53.

21. Scheinfeld NS. Seborrheic dermatitis. Skinmed. 2005;4(1):49-50.

22. Kawakami Y, Nakamura-Wakatsuki T, Yamamoto T. Seborrheic dermatitis-like eruption following 
interleukin-2 administration. Dermatol Online J. 2010;16(9):12.

23. Hall VC, El-Azhary RA, Bouwhuis S, Rajkumar SV. Dermatologic side effects of thalidomide in patients with multiple myeloma. J Am Acad Dermatol. 2003;48(4):548-52.

24. Riahi RR, Cohen PR. Dasatinib-induced seborrheic dermatitis-like eruption. J Clin Aesthet Dermatol. 2017;10(7):23-7.

25. Yang $\mathrm{CH}$, Lin WC, Chuang $\mathrm{CK}$, et al. Hand-foot skin reaction in patients treated with sorafenib: a clinicopathological study of cutaneous manifestations due to multitargeted kinase inhibitor therapy. Br J Dermatol. 2008;158(3):592-6.

26. Tsai KY, Yang CH, Kuo TT, Hong HS, Chang JW. Hand-foot syndrome and seborrheic dermatitis-like rash induced by sunitinib in a patient with advanced renal cell carcinoma. J Clin Oncol. 2006;24(36):5786-8.

27. Naranjo CA, Busto U, Sellers EM, et al. A method for estimating the probability of adverse drug reactions. Clin Pharmacol Ther. 1981;30(2):239-45.

28. Shelley WB, Shelley ED. Scrotal dermatitis caused by 5-fluorouracil (Efudex). J Am Acad Dermatol. 1988;19(5 Pt 2):929-31.

29. Liu XQ, Zhuang M, Wang Z, Huber RM. Correlation between dihydropyrimidine dehydrogenase and efficacy and toxicity of fluoropyrimidine drugs. Eur Rev Med Pharmacol Sci. 2014;18(18):2772-6.

30. Magné N, Etienne-Grimaldi MC, Cals L, et al. Dihydropyrimidine dehydrogenase activity and the IVS14 + 1G > A mutation in patients developing 5FU-related toxicity. $\mathrm{Br} \mathrm{J}$ Clin Pharmacol. 2007;64(2):237-40. 